\title{
Morpholological Borrowing and Genetic Relationship
}

\author{
A Review Article of Johanson, and Robbeets (eds). 2o12: 'Copies Versus \\ Cognates in Bound Morphology'
}

Harold Koch

School of Literatures, Languages and Linguistics, Australian National University harold.koch@anu.edu.au

\begin{abstract}
This edited volume adds to the literature on language contact. It specifically deals with the borrowing of morphology, and addresses the methodological issue of how to distinguish resemblances that represent borrowing (here called copying) from those that reflect cognation within genealogically related languages. Several studies offer empirical data on the scales of borrowability (or copiability in the terminology of this volume) that have been discovered-comparing morphological to lexical borrowing, inflectional to derivational, and distinguishing the likelihood of various kinds of inflectional borrowing. A number of papers attempt explanations for the scales in terms of semantic, structural or frequency factors. Proposals are also made regarding factors other than borrowing or cognation that may result in the sharing of morphological forms between languages. The findings concerning morphological borrowing are applied to several difficult and unresolved issues of genealogical relationship in languages of Eurasia and the Americas.
\end{abstract}

\section{Keywords}

morphology - borrowing - global copying - selective copying - cognates - genealogical classification

\section{Introduction and Overview}

The book format. The book is based on papers from a workshop "Bound morphology in common: copy or cognate?" held at the $43^{\text {rd }}$ meeting of the Societas 
Linguistica Europaea, Vilnius, Lithuania, September 2010. This is a substantial book, consisting of 455 pages, including a language index and subject index plus front matter. The 21 chapters are organised into 2 parts: Part 1 "Theoretical and typological issues" contains 11 chapters; Part 2 "Case studies", is divided into sections on America (chapters 8-11) and Eurasia (chapters 12-21). The first chapter, by the editors (Lars Johanson and Martine Robbeets, "Bound morphology in common: copy or cognate?"), surveys the issues dealt with in the volume and summarises the contents of the remaining chapters.

The topic. The book joins a long series of recent books on language contact in general (Thomason and Kaufman, 1988; van Coetsem, 2000; Thomason, 2001; Winford, 2003; Matras, 2009; Hickey, 2010) and more specifically on contact affecting grammar (Heine and Kuteva, 2005; Matras and Sakel, 2007; Aikhenvald and Dixon, 2008). This book is more specifically focused on morphology. While it is broadly about the copying or borrowing of morphology, it concentrates on an even narrower issue: how to decide whether shared morphology reflects contact rather than genetic relationship (or something else). The contributors are not only concerned about theoretical issues of which aspects of linguistic structure can or cannot be borrowed or which are more or less likely to be borrowed but also wrestle with the practical issue that historical linguists face of how to decide whether resemblant features in particular languages are the result of copying/borrowing (i.e. contact) or are to be interpreted as cognate material inherited from a common proto-language and therefore diagnostic of genetic relationship. This problem supplies the phrase "copies versus cognates" of the title. Considerable attention is also devoted to other possible explanations for shared linguistic features.

Terminological framework. The terminology used by most of the contributors is that of Johanson's Code Copying Model (2002). In this system the process is called 'copying' from a 'model' language to the 'basic' language. A distinction is made between 'global' copying, which involves the transfer of phonological material along with meaning, etc., and 'selective' copying, which replicates the semantics/function, combinatory patterns, frequency, etc. but not the phonological substance of the source. Table 1 summarises these terms and compares them to the equivalent terms used by other scholars.

A word is required on what counts as 'copying' (or borrowing) and what is not included in these studies. Generally excluded from consideration here are mixed languages, imperfect learning situations, code-switching, the use of foreign morphemes in foreign words only, and the use of foreign affixes in a different 
TABLE 1 Comparison of terminology.

\begin{tabular}{|c|c|c|c|c|c|}
\hline & process & & & language & \\
\hline Johanson & copy & global copy & selective copy & basic & model \\
\hline traditional & borrow & direct transfer & $\begin{array}{l}\text { indirect } \\
\text { transfer }\end{array}$ & recipient & source \\
\hline Matras \& Sakel & replicate & matter & pattern & & \\
\hline Grant & transfer & fabric & pattern & & \\
\hline
\end{tabular}

function, e.g. as part of the stem in the borrowing language. (Chapters by Gardani (ch. 4) and Eliasson (ch. 12) are the most explicit about the criteria for borrowing.)

Structure of the review. In the following I discuss the book according to the themes that are covered. Individual chapters are cited with the full name of the author(s) and full chapter title at their primary mention, and otherwise are referred to simply by author's surname and chapter number.

2 Copiability Scales

Borrowability hierarchies and constraints. One of the main concerns in the literature on linguistic contact is the relative ease with which different aspects of linguistic structure can be copied; this is referred to as a "borrowing scale" (Thomason, 2001: 70) or a "hierarchy of borrowability" (Winford, 2003: 51). A number of papers in this volume are concerned with such copiability scales. Comparison is made between: lexical vs. morphological elements, bound vs. free grammatical elements, derivational vs. inflectional elements, and various kinds of inflections according to their semantic or structural properties. Contributors advance claims both about the empirical evidence for such scales and the factors that explain these findings. One contributor, Victor Friedman, however, expresses scepticism toward the attempt to formulate constraints: "the typological quest for constraints on borrowability is a quest for a will-o'the-wisp" (323). There is in this book no attempt to relate scales based on language-internal features to those based on extralinguistic factors.

Vocabulary vs. morphology. Anthony Grant (ch.5: "Bound morphology in English (and beyond): copy or cognate?") attempts to "test the extent to which inflectional and productive derivational morphological strata in a language are 
more immune to borrowing than the lexicon is" (99). His evidence comes from English and 13 other languages selected on the basis that they have replaced a high proportion of their basic vocabulary through borrowing - over $10 \%$ of the Swadesh 100-item list. For each language he indicates: the percentage of loans on the Swadesh 100 and 215-item lists and a larger lexical sample; whether they have borrowed function words, bound derivational morphology, free inflectional morphology, ${ }^{1}$ and bound inflectional morphology; and which of 44 items of morphosyntax from his test list have been borrowed. He also presents a comparative table showing the relative amount of contactinduced influence in the phonetics, phonology, inflectional morphology, syntax, and lexicon of each of the languages. He finds only a weak correlation between heavy lexical borrowing and "the extensive replacement of bound and other structural morphemes via borrowing" (119). A number of languages (e.g. Yapese) that have replaced much of their basic lexicon by loanwords have borrowed no "structural morphology" (i.e. bound or free morphology) at all $(106,120)$.

Éva Á. Csató (ch. 17 "On the sustainability of inflectional morphology") discusses the situation of Karaim, a Turkic language spoken in Lithuania, which has had long-lasting asymmetrical contact with Lithuanian and several Slavic languages. It has copied a large number of lexical items, adopted the phonological features of palatalised and non-palatalised consonants, and changed its word order to SVO. While it has borrowed a few bound derivational suffixes (markers of female and adjectival), its "inflectional bound morphology...has maintained its clear Turkic characteristics" (375). These include markers of number, case, possessor person-number, comparative in the nominal system, and of tense-aspect, mood, and subject person-number in the verbal system. Where Karaim has developed new morphosyntactic categories, it has selectively copied features of the model language onto native material (see section 4).

The paper by Salomé Gutiérrez-Morales (ch. 10: "Morphological borrowing in Sierra Popoluca") throws up an apparent exceptional case of morphological without lexical borrowing. This counterexample, however, disappears when the correct contact languages are identified (see section 5 below).

Free vs. bound forms. Grant finds a robust borrowability cline among the "structural elements" in the sample: functional words > (more than) bound derivational morphology $>$ free inflectional morphology $>$ bound inflectional

1 By "free inflectional morphology" he apparently means non-bound markers of morphosyntactic information; i.e. function words. 
morphology. He finds (117): "Function words...are borrowed more easily than items of bound derivational morphology, which themselves are borrowed and integrated...more easily than items of bound inflectional morphology."

The study by Dik Bakker and Ewald Hekking (ch. 9 "Constraints on morphological borrowing: Evidence from Latin America") is based on large corpora of spoken language, from which conclusions are drawn about the extent of borrowing from Spanish into each of three Amerindian languages: Quechua (in Ecuador), Guarani (in Paraguay) and Otomi (in Mexico). While all three languages have borrowed a considerable amount of lexical items and free grammatical words, "there is actually hardly any systematic and autonomous borrowing of bound morphemes from Spanish in any of the three languages" (199). The only clear cases of borrowing of bound forms are: the feminine - $a$ used in Otomi be:ta 'granddaughter' (vs. be:t'o 'grandson') and the agentive suffixes -ero and -dor in Quechua. A few more affixes, plural -s, diminutive -ito, and more instances of agentive -ero and -dor, were found in Spanish loanwords, but these do not count as copies into the native languages.

Alexandra Y. Aikhenvald's contribution (ch. 8 "Invisible' loans: How to borrow a bound form") might appear to be an exception to Grant's findings. She describes a situation in the Vaupés River Basic of north-west Amazonia where, despite intensive contact between Tariana (an Arawak language) and East Tucanoan languages, direct borrowing of lexical and grammatical forms is rather limited. This is explained by a linguistic ideology which discourages the transfer of obvious forms between languages. Of the forms identified as borrowed from Tucanoan into Tariana, Aikhenvald lists 17 verbal roots and three manner enclitics. A handful of nouns are shared, without the direction of borrowing being clear. Most of the borrowed verbs are adapted by means of a Tariana verbalising suffix and take Tariana inflectional prefixes, suffixes and enclitics. ${ }^{2}$ She suggests that verb roots are tolerated as loans because they are less visibly linguistic imports when they are preceded and followed by native affixes. (For the more prevalent practice of calquing foreign forms, see section 4.)

Derivational vs. inflectional morphology. Grant (ch. 5) finds that in his sample bound inflections are rarely borrowed, most inflections being rather inherited

2 Because verb roots never appear on their own, as free forms, Aikhenvald treats them as bound forms and uses this fact in support of a claim that this situation "goes against popular belief that free morphemes are easier to borrow than bound ones" (167). The chapter is not very explicit, however, on the status of each of the borrowed forms in the source language. At any rate, given the bilingualism of the Tariana, it can be assumed that its speakers are well able to isolate the lexical roots of the forms that are copied. 
(104), and concludes that his study "suggests that bound inflectional morphology is the least easily borrowed kind of morphology" (106). He finds a few borrowed inflectional markers, however: Ngandi (Gunwinyguan, Australian) case suffixes, Garifuna (Arawak) noun plural, KiUnguja (Bantu) verbal TAM markers, and borrowed derivational markers: Kalderash Romani ordinal numeral and abstract nouns formations, and Siwi Berber (Afroasiatic) templates borrowed from Arabic for the formation of deadjectival abstract nouns, comparatives, and agent nouns.

Stig Eliasson (ch. 12: "On the degree of copiability of derivational and inflectional morphology: Evidence from Basque") "surveys the extent to which Basque has adopted overt derivational and inflectional elements" (259) over the course of its two-millennia-long contact with the Romance languages. He finds that "the Basque case of language contact adheres neatly to the notion of differing copiability of derivational and inflectional affixes in historical linguistics" (289).

About half of the vocabulary of Basque has been borrowed from Latin or Romance (267). In morphology, the derivational > inflectional hierarchy is present: "Basque has copied suffixal derivational morphology extensively...and its inflectional morphology has, with some important exceptions, been totally impervious to cross-linguistic copying" (262). According to the sample, from $30-50 \%$ of Basque derivational affixes are considered to be borrowed (271). An instance of inflection that has been borrowed is gender: in some dialects gender marking has been extended from Spanish loans álto vs. álta 'tall' (masculine vs. feminine) to a few indigenous terms such as sorristo, sorrista 'lousy' (279). No borrowed inflections of case, number, or definiteness were found. No verbal inflections were borrowed, except $-t u$ from the Latin perfect participle, which has become "exceedingly productive" $(282)$. This form is regarded as a mixed derivational/inflectional suffix.

Francesco Gardani (ch. 4: "Plural across inflection and derivation, fusion and agglutination") mentions the rarity of borrowing of inflectional morphology compared to word formation and establishes that "some morphological categories, in particular nominal plural, are more likely to be borrowed" (72). The data he discusses consists of borrowed inflectional affixes in some twenty languages-expanding the database of his earlier study (Gardani, 2008). He proposes both semantic and structural reasons for the relative frequencies of copying that he has found (see below section 3).

Inflection according to category. Gardani (ch. 4) finds that plural is borrowed much more frequently than other inflections: about a third of his reliably established examples of borrowed inflections involve markers of (nominal) 
plural. He finds that the majority of borrowed inflections belong to the class of "inherent inflections", of which plural as a prototypical member (see section 3 below).

Janhunen (24-25), without giving a detailed explanation, claims that it is the grammatically "more peripheral" morphological categories (derivational affixes, participles/converbs) vs. the more central categories of grammatical structure (case, person, tense-aspect) that are more easily borrowed.

\section{Explanations for Direct Borrowing}

Semantic factors. Gardani (ch. 4) makes a distinction between inherent and contextual inflections. While the latter mark features from outside of the lexeme (such as person-number agreement on verbs, gender agreement on adjectives, syntactic case on nouns), the former are not context-sensitive. Examples of inherent inflection are number, gender and semantic case on nouns, and tense and aspect on verbs. Inherent inflections are thus more similar semantically to derivational markers. This semantic dependence of the inflectional categories accounts for their greater liability of their markers to be borrowed along with their lexical bases.

Ad Backus and Anna Verschik (ch. 6 "Copiability of (bound) morphology") are concerned with explaining the copiability scales that have been found. They report (125) the implicational hierarchy found by Field (2002): content item $>$ function word $>$ agglutinating affix $>$ fusional affix; their main concern, however, is to account for the "attractiveness" of the linguistic elements that explains their copiability. They argue for semantic specificity as the main determinant of direct copying. Culturally specific words are more specific than basic vocabulary items, which are more specific than derivational markers, and grammatical markers are the most general.

The more an element is located towards the specific end of this continuum, the more copyable it is, because there is unlikely to be a native element that matches its semantics completely. The more general the meaning, the less attractive the element is. (139).

They include perceptual salience in their definition of specificity, to account for the ease with which discourse pragmatic words are directly borrowed. For their explanation of selective copying, see section 4 below.

Structural factors. Formal linguistic properties are considered by a number of contributors to be relevant to copiability. Eliasson (262) says: 
Looking behind grammatical categories such as derivational/inflectional, suffixal/prefixal, nominal/verbal, non-finite-finite, however, we discern also in Basque that it is rather formal properties like donor-language transparency, recipient-language cohesion, and donor/recipient structural equivalence that allow for cross-linguistic copying of bound morphology to take place.

Structural properties of the donor language. Grant (115ff) refers to the findings of Heath's (1978) study of language contact in north-eastern Arnhem Land, Australia, which he considers "still a valid contribution to the field of the study of contact-induced change" (115). Heath identified five structural features that favour the direct copying of bound morphemes. Grant summaries Heath's claims as follows (115f): "those forms which constitute distinct and easily perceptible syllables (especially cv syllables), and which have a single major functional role in the structure of the language which can be easily recognised and apprehended by listeners, and which are equipped with shapes that are not easily confused with those of other forms which appear in the same slot, are the kinds of morphemes which are most easily transferred from one language to another."

Gardani (ch. 4) also cites Heath's results and explains them in terms of Natural Morphology.

...morphemes that respond to requirements of naturalness by displaying properties of agglutination such as morphotactic transparency (sharpness of boundaries) and biuniqueness (monofunctionality) are more likely to be borrowed than morphemes that display properties of fusional morphology, since they serve performance in communication and cognition more efficiently. (92)

Eliasson (ch. 12) comments that the affixes which have been borrowed into Basque are characterised by "ease of segmentability in the donor language" and "perspicuity and specificity of category-marking" (287).

Recipient language cohesion. Eliasson (ch. 12) cites the tightly structured organisation of the Basque verb inflectional subsystems as a providing a "robust structural barrier to any kind of copying of Latin/Romance verb inflections" (287).

Backus and Verschik (ch. 6) mention structural coherence, such as the organisation of inflectional morphemes into tight paradigms, as a factor in borrowing but claim that this "is a corollary of general meaning" (135), and hence of less significance than the semantic generality of the forms. 
Typological (dis)similarity. Several authors allude to the role of typological similarity or dissimilarity in facilitating or impeding morphological borrowing respectively. Janhunen says (24): "Borrowing (copying) in bound morphology is a phenomenon favoured by typological similarity between the interacting languages", and points to the problem this poses for evaluating similar morphology in closely related languages.

Backus and Verschik refer (126) to Field's (2002) "principle of system incompatibility", which affects the evaluation of the "attractiveness" to borrowing of morphemes between particular pairs of languages. Grant asserts that "typological dissimilarity...may impede extensive transfer of morphemes which cannot easily be detached and isolated" (117). Bakker claims that "[w] holesale morphological diffusion is...difficult to imagine for polysynthetic languages, and commonalities are more likely to be inherited" (251). Eliasson attributes that virtual absence of borrowed prefixes in Basque to "inter-language structural incompatibility" (259, cf. 287), since Basque structure hardly includes any prefixes. F. Josephson claims that "[s]tructural dissimilarities account for the lack of transfer of morphemes and grammatical elements from Hurrian and Hattic" [into Hittite and Luvian] (337). Bakker and Hekking suggest that the differences in borrowing of grammatical material in Quechua, Guarani, and Otomi may be due to differences in typology (216).

\section{4}

\section{Indirect Borrowing}

Selective copying. The Code Copying Model describes all kinds of indirect borrowing as selective copying, which unlike global copying does not replicate the material (phonological form) but takes on semantic/functional, combinatorial, and/or frequency properties from the source language.

Csató's discussion of Karaim (ch. 17) shows how "[s]elective copying has introduced functional equivalents of foreign models without any global copies of foreign morphology" (379). She describes how Karaim has developed two new morphosyntactic categories, an instrumental case and a modal auxiliary, modelled on the pattern of Russian but using native material.

Aikhenvald (ch. 8) describes as "grammatical accommodation" the "adjustment of form and meaning of a morpheme to make it similar to a look-alike in the contact language" (178). Most of her examples can be regarded as instances of selective copying. She describes five grammatical markers that can be explained as Tariana accommodation of its forms to the functions of Tuconoan morphemes of similar form; these include markers of imperative, hortative, and an evidential (inferred from visual traces). 
Folke Josephson (ch. 15 "Transfer of morphemes and grammatical structure in Ancient Anatolia") argues that a number of morphosyntactic changes in the history of Hittite can be ascribed to selective copying from Luvian in a context of heavy Luvian-Hittite bilingualism. He rejects, however, suggestions there was any structural borrowing from either Hurrian or Hattic into the IndoEuropean languages, Hittite and Luvian, except for a single instance of a bound morpheme in the Kizzuwatna variety of Luvian (for which he provides only an indirect reference).

Frequency. Backus and Verschik (ch. 6) attribute the copying of patterns (selective copying, indirect borrowing) to their high frequency, which entrenches them in their speakers' mental representations and enables them to be used by fluent bilinguals with new lexical material—especially "if use of the basic language by those same speakers falls below a certain threshold, so that the degree of entrenchment of the model language structure is higher than that of the basic language equivalent" (143).

Nikki van de Pol's contribution (ch. 13 "Between copy and cognate: the origin of absolutes in Old and Middle English") provides a nice example of selective frequency copying. She examines the absolute construction of Old and early Middle English, which involves a subordinate clause whose subject is typically not coreferential with elements in the matrix clause, whose predicate is a participle, and where the nominal subject and participle are in an oblique case. Using her own corpus research and Johanson's code copying model, she proposes a new solution to the controversy over whether the construction is a native Germanic one or results from borrowing the model of Latin during an era of heavy translation. She proposes that the construction was indeed inherited within Germanic, and was becoming moribund in Old English, but that the frequency of the Latin constructions in texts that were being translated reinforced the indigenous construction and occasioned a temporary reversal of the trend towards disappearance.

\section{5}

\section{Neither Copy Nor Cognate}

A number of chapters discuss reasons other than straightforward borrowing or cognation that may be responsible for morphological similarities.

Variability in proto-language plus drift. Brian D. Joseph (ch. 7 "A variationist solution to apparent copying across related languages") proposes a solution for "the problem raised by the occurrence of similar grammatical developments in 
two related languages where appealing to common inheritance is not possible" (151). He suggests that the common proto-language may have included variant forms or patterns, one of which was sociolinguistically suppressed, and that the submerged variant later surfaced in both languages. His grammatical example is the use of the genitive case for functions formerly marked by the dative, in late but not earlier stages of both Sanskrit and Avestan. Thus "parallel developments can reflect inheritances into each language of variants that existed in the proto-language." (160).

Convergent development. Juha Janhunen (ch. 2 "Non-borrowed non-cognate parallels in bound morphology: Aspects of the phenomenon of shared drift with Eurasian examples") defines a concept of "shared drift" as "a process in which two or more contacting languages develop both formally and functionally similar elements out of originally different sources" (42). While this phenomenon presupposes contact, one could be misled if the results are taken as evidence either for direct morphological borrowing or for genetic relationship. Shared drift involves "a process of selection, in which each of the contacting languages opts for similar solutions in order to create an 'illusion of relationship' where no actual relationship is necessarily present" (25). This paper shows that "several of the most conspicuous morphological similarities even between the 'core Altaic' [Turkic, Mongolic, Tungusic] families, the traditional cornerstone of Altaic comparative studies, are actually illusions created by shared drift" (42).

Convergent development is also invoked by Johanna Nichols (ch. 3 "Selection for $m: T$ pronominals in Eurasia"). Nichols describes the correlation in personal pronouns and pronominal affixes between marking of first person by morphemes beginning with $m$ and second person with an initial apical or palatal obstruent $(t, s$, etc.) in a number of language families originating in central Eurasia-Indo-European, Uralic, Turkic, Mongolic, Tungusic, and Kartvelian. On the basis of statistical studies of the forms in numerous languages of these families she concludes that $1 \mathrm{Sg} m$ and the $m-T$ systems in general behave as what is called "attractor states" in complex systems theory: i.e. "a state that is easier to enter than to leave, and which is numerous and/or expansive as a result" (48). For example, oblique forms of $1 \mathrm{Sg}$ which begin with $m$ are stable in many of the languages and there are many instances of non- $m$ forms of the $1 \mathrm{Sg}$ Nominative pronoun being replaced by forms with $m$. The morphological sharing of $m$ should not therefore be taken as strong evidence for a distant genetic relationship: "A reconstruction should include only what cannot be explained by universal pressures on the daughter languages, so unless there is firm evidence to the contrary an attractor state can most parsimoniously be assumed 
to be a target of convergence rather than an original ancient form" (56). She proposes that the sociolinguistic factors around the Eurasian steppes may have contributed to this convergent selection of linguistic features-in particular the free dispersal and expansion of small population groups with "no overarching prestige variety and no strong language loyalty" (57).

Victor Friedman (ch.14 "Copying and cognates in the Balkan Sprachbund") discusses an interesting case of parallel development in Romani and Turkish. Certain Romani dialects of Greece, eastern Bulgaria, and the Crimea have created a $2^{\text {nd }}$ plural verb suffix -anas, by combining the Turkish suffix - nIz with the Romani suffix -an, then in analogy to this form converted their inherited $1^{\text {st }}$ plural -am to -aməs. Although various Turkish dialects have similarly extended the disyllabic ${ }_{2} \mathrm{Pl}$ suffix to ${ }_{1} \mathrm{Pl}$, attention to the geographic distribution of the relevant dialects shows that these historical developments must have been independent in the two languages.

Language-internal explanations. Friedman (ch. 14) furthermore carefully analyses the oft-cited example of Meglenoromanian (Romance) verbal inflections $-m 1 S g$ and $-s ̌ 2 S g$, which have been ascribed to borrowing from Macedonian (Slavic). Friedman identifies other verbal paradigms within Meglenoromanian itself from which the suffixes could have been taken and indicates factors of sound change which might have motivated the replacement of the inherited endings in verbs with certain phonotactic properties. Doubt is cast on the borrowing scenario also by the fact that the dialects of the most heavily slavicised villages did not participate in this innovation.

Intermediary languages. Sometimes the explanation for resemblances between two languages is to be found in the role of a third language. Morales' careful study (ch. 10) investigates what appears to be a borrowing of the Spanish derivational agent suffix -ero into Sierra Popoluca, as -teeroj-which is surprising given the absence of a large number of pairs of borrowed lexemes with and without the suffix and the relatively short period of intensive contact between the two languages. Closer study reveals that the Spanish suffix was rather borrowed and adapted into some of the Nahuatl languages and that Sierra Popoluca must have acquired this reanalysed derivational suffix from Pajapan Nahuatl, with which it had a long and intense contact.

Judith Josephson (ch. 16 "The historical background of the transfer of a Kurdish bound morpheme in Neo-Aramaic") proposes that the preverbal particle (or prefix) be marking futurity and related modal senses in Northeastern Neo-Aramaic (NENA) dialects, spoken in northeastern Iraq and southern Azerbaijan, was one of a number of grammatical forms borrowed from Kurdish, 
in which speakers of NENA are bilingual, Kurdish $b e-/ b i$ - in turn was copied from Persian, in which preverbal be resulted from the grammaticalisation of an adverbial $b \bar{e}$ 'out, away'.

A number of contributors apply conclusions about the possibility of morphological borrowing to problems in the classification of particular languages.

Lindsay Whaley (ch. 19 "Deriving insights about Tungusic classification from derivational morphology") explores the possibility of using evidence from shared morphological markers of "Aktionsart" (aspect, mood, spatial distribution) categories to answer questions about the internal structure of the Tungus family which cannot be firmly established by the criteria of lexical cognates and sound correspondences because of the prevalence of borrowing and other language contact effects. Comparison of productive suffixes largely supports the accepted understanding of the internal classification of the languages; this case would be strengthened if it could be established that the shared forms are indeed innovations of particular subgroups. It is noted that "non-productive derivational morphology often reflects linguistic material that has been present in a language for long time periods" (406). Although it may therefore be expected to provide evidence of relatedness at greater time depths, there are problems in evaluating it. Methodological problems in the use of non-productive suffixes are canvassed, including the occurrence of a suffix on a single verb root, determining whether short suffixes of similar form but somewhat different semantics are indeed cognate, how to deal with gaps in the documentation of language varieties. A possible approach, that is not discussed, is to establish to what extent the suffixes can be analysed etymologically in terms of derivation from the combination of a participial form and an inflected verb, as was demonstrated for the Completive form -matว of Oroqen (403); then it might be possible to compare some suffixes to verb roots occurring in related languages. Issues of the copying of bound morphology are not explicitly addressed in this chapter. It can probably be assumed, however, that such suffixes are likely to constitute evidence for genetic relationship except in the case of those shared suffixes which are attested only on a single verb (hence the combination of root and suffix may have been borrowed) or where similar forms are the result of contact-motivated parallel grammaticalisations of a participial plus a verb, for example.

J. Marshall Unger (ch. 20 "The likelihood of morphological borrowing: The case of Korean and Japanese") is a critique of Vovin (2009), whose attempts to 
refute the etymological evidence provided by Samuel Martin, John Whitman, and Bjarke Frellesvig in support of a genetic relationship between Korean and Japanese relies heavily on claims of borrowing and linguistic convergence. Vovin apparently treats the suggested cognate function morphemes as either non-cognate on the basis that their functions do not match closely enough or that they are not attested in Eastern Old Japanese or in the Ryūkyūan languages or as borrowings from Korean into Japanese during the first millennium BCE. Unger argues that these scenarios are unrealistic and in particular that the morphological borrowing required is not consistent with the social conditions of contact that obtained.

Peter Bakker (ch. 11 "Cognates versus copies in North America: New light on the old discussion on diffusion versus inheritance") discusses the possibility of a genetic relation among the polysynthetic language families of the North American west coast and inland: Salish, Algonquian, the isolate Kutenai, and the Chimakuan and Wakashan families. He calls attention to the similarities in their verb structures, both in the order of affixes and the semantics of the verbal categories, in their hierarchical alignment systems, and lexical suffixes. Patterns which are both typologically rare and not easily explicable by motivations from semantics or grammaticalisation, he claims, are indicative of a historical connection-either genetic relation or contact. He considers the usual explanation in terms of areal contact to be unsatisfactory, since it assumes processes of morphological diffusion that are unprecedented. He concludes (252) that "[t]he Algonquian-Salish connection is therefore more likely to be genealogical than areal", while admitting that such a relationship is not demonstrable through cognates and/or sound correspondences.

Martine Robbeets (ch. 21 "Shared verb morphology in the Transeurasian languages: copy or cognate?") uses morphology to explore the genealogical relations among the "Transeurasian" (Japonic, Koreanic, Tungusic, Mongolian and Turkic) languages. This is the disputed "Altaic hypothesis". She addresses the two major objections that have been raised to this posited genealogical relation, that the languages lack sufficient shared bound morphology and that all similarities can be attributed to code-copying. Robbeets proposes twelve "guidelines for the distinction between copies and cognates" (428) - six that are likely indications of code copying and six that rather support a genealogical relationship. She then presents tables showing 21 verb suffixes that previous research has advanced as cognate between Japanese and the other languages and applies these tests to the proposed etymologies. She concludes that "none of the indications of codecopying....are fulfilled", whereas a number of the cognate indicators are satisfied; it is "therefore safer to identify the shared verb 
morphemes in the Transeurasian languages as cognates than it is to consider them as copies" (443).

This discussion is probably not sufficient to convince sceptics. While the likelihood of the compared forms being copies is indeed slim, there is still the possibility that some of the tentative cognates rather represent chance resemblances. ${ }^{3}$ Almost all of them are short, consisting of only a CV syllable or a single segment (consonant or vowel). Their meanings are also rather general: five are glossed as "(ad)nominal finite", and two each as "causative-passive" and "anticausative-fientive". Furthermore, some of the tests seem to have been applied in a rather artificial manner. For example, it is odd to describe a resultative deverbal derivative as instantiating the cumulative exponence of the properties deverbal noun and resultative aspect.

Tooru Hayasi's contribution (ch.18 "Foreign and indigenous properties in the vocabulary of Eynu, a secret language spoken in the south of Taklamaklan") involves the classification of a single language. Eynu is a register used for communication with insiders by small groups of people, called Abdal by the Uyghur, who live in the south-western part of the Xinjiang Autonomous Region of China and whose everyday language is Uyghur. Eynu consists of only a few hundred semantically basic content words which differ from Uyghur, but shares function words, bound morphemes and word order with Uyghur. Hayasi shows that the lexical structure of Eynu - the construction of idioms, derivational paradigms, even the homonymy of 'fire' and 'grass' - are modelled on Uyghur. The majority of non-Uyghur words are traceable etymologically to Persian.

The common historical explanation is that Eynu constitutes the last remains of the ancestral language of Persian-speaking Abdals, who shifted to the dominant Uyghur language, whose influence led to "a complete morphosyntactic restructuring" (386) of their heritage language. Hayasi proposes an alternative historical scenario, in which the Abdal people created a secret code by copying the phonological form only of Persian words which they happened to know and grafting this form onto the existing lexical features of Uyghur words. This process is compared to the "relexification" Muysken posits for Media Lengua, which uses Spanish lexical stems with Quechua morphology. ${ }^{4}$ In this new historical interpretation, it should be noted, Eynu is not an example of

3 Note also the caveat from Janhunen about the illusory nature of some Altaic morphological resemblances (section 5 above).

4 This is described as "selective copying" in Johanson's terminology; however, in the Code Copying Model this term usually refers to the copying of features other than the phonological material. 
morphological borrowing at all; in the traditional scenario, on the other hand, it illustrates massive borrowing of both derivational and inflectional bound morphology. The issue can probably only be resolved by a better understanding of the historical social situation. The situation of Eynu, it seems to me, bears comparison with that of Ma'a and Angloromani (cf. Thomason, 2001: 199-200).

Questions of linguistic contact vs. genealogical relation can obviously be answered more easily if close attention is paid to the chronological, spatial, dialectological, and social detail of the language contact situation. This is emphasised especially in the four case studies from the Balkans contributed by Friedman (ch. 14).

While many of the studies here mention aspects of the social background to the linguistic contact they discuss, not much prominence is given in this book to extralinguistic factors such as the extent of multilingualism, intensity and duration of contact, and social, economic, political, and demographic relations between the groups in contact. Probably the chapter that emphasises the social background the most is that of Aikhenvald (ch. 8), who highlights the social background of "obligatory societal multilingualism which follows the principle of linguistic exogamy" (169) and the ideology of avoiding overt language mixing.

\section{8}

\section{Conclusion}

The book is in general well produced. I noted only a small number of typographical errors. ${ }^{5}$ A few references were missing. ${ }^{6}$ A few examples of idiosyncratic wording were found. ${ }^{7}$ I have noted a couple of instances of an omitted interlinear gloss. ${ }^{8}$ These few faults, however, hardly detract from what is a

537 fried for friend (37), 1890 for 1980 (67), Slavic for Romance (82), dar for dark (132), Rod M.W. Dixon for Robert M.W. Dixon (147), -abel for -able (225), Meyers-Scotton for Myers-Scotton (334), share innovations for shared innovations (405 twice), be though for be tough (?) (441).

6 Field (2002), Meillet (1921), Moravcsik (1978), Schuchardt (1884), Weinreich (1953) in chapter 3 ; Kloekhorst (2008) in chapter 15 .

7 Rhotation for rhoticisation $(27,29)$, variation between copyable and copiable (chapter 6), classical for classic (284), opacation (271), at my diposition for at my disposal (367).

8 Examples (7) and (30) of chapter 4. 
handsome and valuable volume. The publishers, editors, and contributors deserve to be congratulated on the result. This work should be considered essential reading for all who are interested in language contact, morphology, and the methods of historical linguistics. It should be consulted both for the interesting data it presents and for the issues it wrestles with.

\section{References}

Aikhenvald, Alexandra Y. and Robert M.W. Dixon. (eds.). 2008. Grammars in contact: A cross-linguistic typology. (Explorations in Linguistic Typology 4) Oxford: Oxford University Press.

Field, Frederic. 2002. Linguistic borrowing in bilingual contexts. Amsterdam: John Benjamins.

Gardani, Francesco. 2008. Borrowing of inflectional morphemes in language contact. (European University Studies Series XxI Vol. 320) Frankfurt am Main: Peter Lang.

Heath, Jeffrey. 1978. Linguistic diffusion in Arnhem Land. Canberra: Australian Institute of Aboriginal Studies.

Heine, Bernd, and Tania Kuteva. 2005. Language contact and grammatical change. Cambridge: Cambridge University Press.

Hickey, Raymond. 2010. The Handbook of Language Contact. Oxford: Willey-Blackwell. Johanson, Lars. 2002. Structural factors in Turkic language contacts. Richmond, UK: Curzon.

Johanson, Lars and Martine Robbeets (eds). 2012. Copies versus cognates in bound morphology (Brill's Studies in Language, Cognition and Culture 2) Leiden/Boston: Brill.

Matras, Yaron. 2009. Language Contact. (Cambridge Textbooks in Linguistics) Cambridge, uk/New York: Cambridge University Press.

Matras, Yaron and Jeanette Sakel (eds.) 2007. Grammatical borrowing in cross-linguistic perspective. (Empirical Approaches to Language Typology 38) Berlin/New York: Mouton de Gruyter.

Thomason, Sarah G. 2001. Language contact: an introduction. Edinburgh: Edinburgh University Press.

Thomason, Sarah Grey and Terrence Kaufman. 1988. Language contact, creolization, and genetic linguistics. Berkeley: University of California Press.

van Coetsem, Frans. 2000. A general and unified theory of the transmission process in language contact. (Monographien zur Sprachwissenschaft 19) Heidelberg: C. Winter. Vovin, Alexander. 2009. Koreo-Japonica: A re-evaluation of a common genetic origin.

(Centre for Korean Studies Monograph) Honolulu: University of Hawai'i Press.

Winford, Donald. 2003. An introduction to contact linguistics. Malden, MA/Oxford, UK. 